|

\title{
Positive for Youth Progress since December 2011
}

\author{
July 2013
}




\section{Contents}

$\begin{array}{ll}\text { Table of figures } & 3\end{array}$

$\begin{array}{ll}\text { Foreword } & 6\end{array}$

$\begin{array}{lr}\text { Introduction } & 7\end{array}$

What has been achieved since the publication of Positive for Youth? 9

Young people at the heart of policy making 9

Shaping policy at the National Level 10

Young people at the heart of major Government reforms 12

$\begin{array}{ll}\text { Young people at the heart of local delivery } & 19\end{array}$

The impact of Positive for Youth 25

Increasing numbers of young people in education and work-based learning, and increases in attainment levels $\quad 25$

Young people are leading safer and healthier lives... $\quad 27$

Young people remain active in their local communities.... 28

Young people generally feel a sense of well-being.... 30

Conclusion: Embedding Positive for Youth 32

Leading by example $\quad 32$

DfE Commitment to young people 33

$\begin{array}{ll}\text { Summary } & 34\end{array}$ 


\section{Table of figures}

Figure 1 Proportion of 18 year olds in Education, Employment and Training (EET) 2007 to 2012

Figure 2 Proportion of 16-17 year olds in Education and Work Based Learning 2007 to 2012

Figure 3 Proportion of 19 year olds achieving Level 3 by FSM status 2007 to 2011

Figure 4 Proportion of 19 year olds qualified to Level 22007 to 2011

Figure 5 Proportion of 11 to 15 year olds who have ever had an alcoholic drink and ever taken drugs 2007 to 2011

Figure 6 Proportion of 10 to 17 year olds who have not had any contact with the criminal justice system (as measured by a reprimand, warning or conviction) 2006 to 2011

Figure 7 Under 18 years conception rate in England 2006 to 2011 


\section{Case Studies and Commitments}

Across Government

The Government is committed to continuing to listen to and work with young people.

The Government is also working with young people to help them avoid risky behaviours and lead safer lives.

Securing young people's well-being

Youth Contract for $16-17$ year olds

Policy Framework for young people

The Government is committed to the vision that all sectors listen to and work with young people

Government is committed to supporting and enabling that good practice to become the norm.

Cabinet Office

In 2013, around 50,000 places will be available on NCS. In 2014, we will make around 90,000 places available.

NCS Graduates

Youth United Foundation

The Campaign for Youth Social Action

Mutuals and joint venture partnerships

Developing Mutuals in Youth Services

Department for Communities and Local Government

Troubled Communities

Unlocking talent

Department for Education

An excellent education for all young people

We are increasing participation and supporting those that need help.

DFE VCS Grants Programme

Putting the power and resources in the hands of those working closest with young people enables them to design and deliver an education that meets the needs of each young person, helping to narrow the attainment gap.

Youth in Action

We delivered our commitment to refresh the statutory guidance to local authorities on youth services 
We have issued guidance to schools and colleges to help them secure high quality, independent careers guidance for young people up to the age of 18 years.

Myplace Centres

Department for Work and Pensions

$\underline{\text { Social Investment }}$

Home Office

The Government is also working with young people to help them avoid risky behaviours and lead safer lives. Acceptable Behaviour Contracts (ABCs)

Ending Gang and Youth Violence Programme

Home Office and NSPCC joint Young People's Panel.

We are supporting areas affected by gangs.

Young People's Advocates

Local Authorities

North Yorkshire Youth Support Service

Milton Keynes Big Youth Debate

Hillingdon Youth Council

Reading Council

Surrey Youth Enterprise workshops

Castle Vale Youth Council

Dorset Children's Services

York Youth Innovation Zone

Bedford Youth Innovation Zone

Reading Young Commissioners

Redbridge Summer Reading Challenge

Voluntary Sector

UK Youth

UK Youth Parliament 2012

New Partnerships - United Futures

We are supporting the voluntary sector.

Outcomes Framework for Young People's Services

Gen2Gen Project

Truth about Youth 


\section{Foreword}

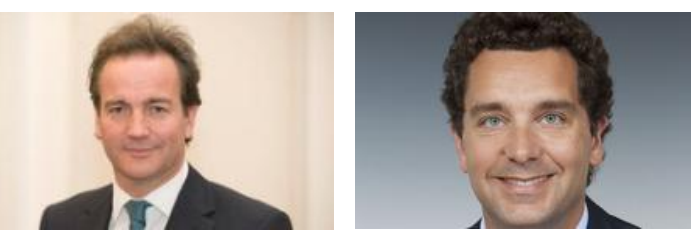

Positive for Youth set out an ambitious vision in which the whole of government and society would support young people to realise their potential. The vision sets out how locally and nationally, and in all sectors - we would work together to make sure that young people have the supportive relationships, strong ambitions and good opportunities they need if they are to succeed; and how we should focus on supporting success rather than preventing failure.

There is no magic solution to addressing young people's needs and no single organisation can do everything. But we do know that working in silos is a recipe for failure!

We need to give everyone - young people, local communities, agencies - on the local and national stage the self-determination to meet young people's needs. We need to encourage them all to innovate and collaborate effectively in order to make the most positive impact with the knowledge, skills and resources they have.

This report shows how we have seen over the past 18 months that, if we support young people and give them the appropriate tools, they can innovate, they can collaborate and they can have an impact .

It is good to see that our vision is beginning to bear fruit with more young people participating in education, employment and training, more young people leading safer, healthier lives, and more young people active locally and nationally. Young people tell us that they generally feel a sense of well-being.

Government and local authorities are also beginning to see their policies and services through the prism of young people. As this report shows, young people are at the heart of shaping and making policy, and at the heart of local delivery. Whole communities not just young people - are benefitting from this early progress.

But there is more that each of us can do.

We need to stop seeing youth issues through the prism of education. Education will continue to play an important role but every government department, every agency, every authority and every community has an equally important role. We need more innovation and better collaboration - not only at the national and the local level but also between them. We all need to celebrate and build on the progress that we have made together.

The Government will lead by example by ensuring the right department leads on specific areas and improving the way that we co-ordinate our work which affects young people and by investing resources where we are the best people to do so. We will give others a sense of ownership by encouraging and enabling them to collaborate and make the decisions where they are rightly the best people to do so. We will listen to young people and those working with them.

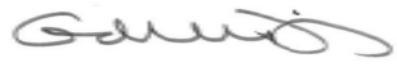

Edward Timpson Minister for Children and Families

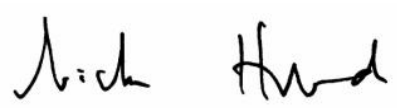

Nick Hurd

Minister for the Civil Society 


\section{Introduction}

Positive for Youth set out a vision of the way in which young people should be supported to realise their potential through the combined efforts of their families, their local communities and the State. It was a joint statement, development by nine Government Departments, working closely with local government and the wider youth sector, and informed throughout by young people themselves. Key to the vision of Positive for Youth is that all those working with young people should accept a stake in their futures - and that young people themselves should inform decisions, shape provision and inspect quality.

The Positive for Youth vision focusses on supporting success rather than preventing failure. Too often, society focuses on the negative aspects of young people - crime, unemployment and engagement with risky behaviours - and forgets the positive contributions of the majority. Positive for Youth highlights how young people can realise their potential through:

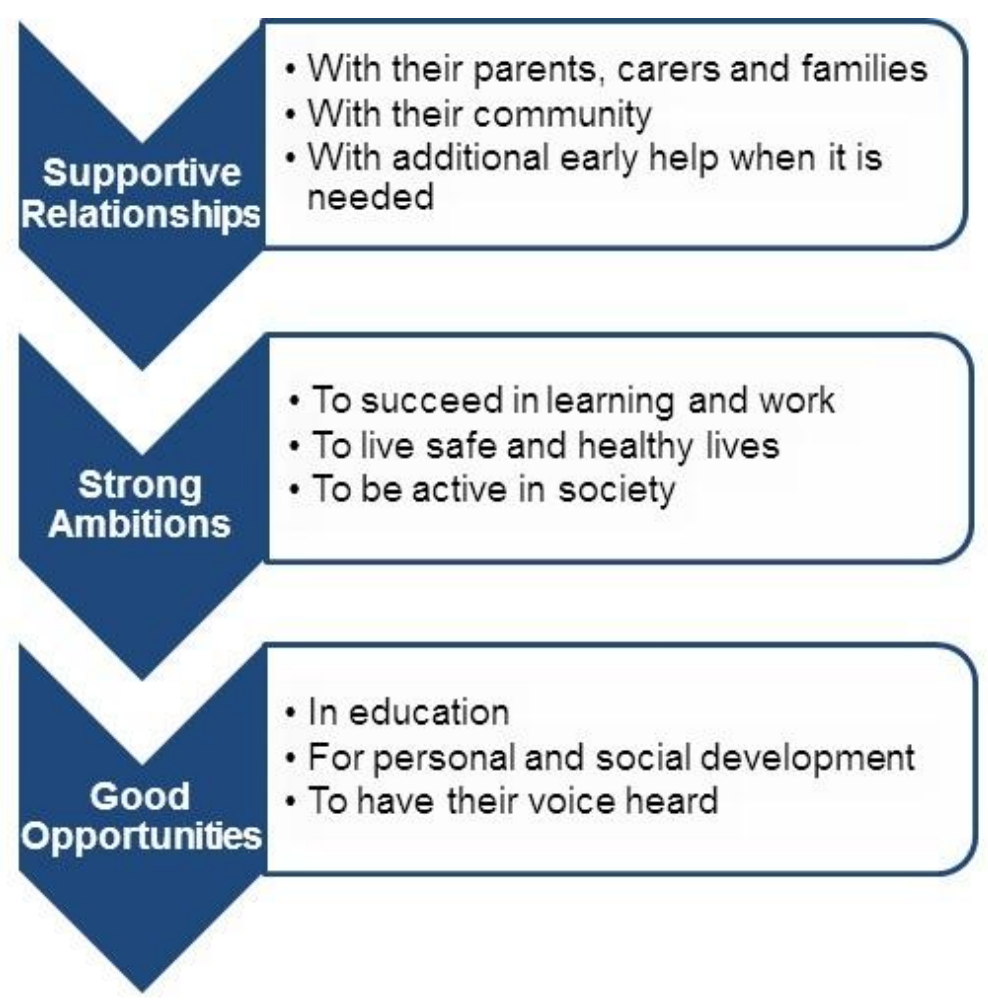

We published Positive for Youth at a time of reducing resources across all public services. Local authorities and their voluntary, community and social enterprise (VCSE) partners are all facing significant financial pressures. But we know that many organisations working with young people are making a reality of the Positive for Youth vision by developing new partnerships and more creative approaches in the delivery of high quality engagement, support and services.

Positive for Youth sets out a vision for the long term, shifting cultural norms and returning power to young people, their families and communities. This document aims to provide a snapshot of progress to date and exemplify the great work going on across the country 
as a call to action for young people and all those who work with them to keep their sights set high. 


\section{What has been achieved since the publication of Positive for Youth?}

Right at the heart of Positive for Youth was the drive to ensure that young people have a say on the issues that matter to them most. A year ago, we said that:

young people have a right to have their views taken into account in all decisions that affect their lives; and

young people have the energy, enthusiasm and valuable ideas for shaping and improving the world around them.

\section{Young people at the heart of policy making}

In communities, we have seen over the past year how the positive contribution of young people in shaping local services gives all young people a greater sense of ownership, which in turn makes services more effective, and a stronger sense of belonging. There has been increased involvement of young people in youth councils and youth cabinets; greater representation of young people on steering and management committees and in the inspection of services; and greater involvement in the development and scrutiny of policies.

The British Youth Council report that up to 19,800 young people, mostly aged between 11 and 17, volunteer their time to represent their peers through Local Youth Councils (LYCs). They are influencing local decision-making and shaping local services for everyone's benefit.

\section{North Yorkshire Youth Support Service}

The Youth Support Service established the "4:05 Club" which runs on a train between Whitby and Danby and is mainly occupied by secondary school students returning home. Young people were involved in the design of the service and suggesting the activities that deliverable in the time and space available. Part of the feedback was that the train becomes too crowded in the summer months when more tourists use the service and the Youth Council is lobbying the train company to add an extra carriage. Making the service more accessible to young people developed relationships and increased the numbers accessing other Youth Support Service advice, help and provision when they need it. Involving young people and seeking their feedback resulted in efforts to improve the train service for all. It worked for the young people and it worked for the community. 


\section{Milton Keynes Big Youth Debate}

70 young people took part in debates with local decision makers including the local authority chief executive and director of children's services, a police chief inspector, local $\mathrm{MP}$, and representatives of political parties. The debates covered issue such as housing youth services, policing, litter, education, cuts and transport. At the end of each debate each decision maker was asked to make a SMART (Specific, measurable, achievable, relevant and time bound) pledge and given three months to complete their pledge.

\section{Hillingdon Youth Council}

The Youth Council consists of elected and co-opted participants who engage with the senior officers and politicians in the Borough's public services, including the local authority, police and public health, on behalf of their peers. It also holds a Youth Conference at which young people can debate issues affecting them and question agencies' senior officers. The Youth Council is a key part of young people's democratic engagement and representation, and acts as a bridge between young people and the agencies, making recommendations to the agencies.

\section{Reading Council}

In Reading, a group of 13 to 19 year old "Young Commissioners" work with the council to make sure services meet young people's needs; selecting service providers, shaping the Sustainable Community Strategy and even recruiting staff.

\section{Shaping policy at the National Level}

The past year has seen a significant increase in the involvement of young people in the development of Government policy. The UK Youth Parliament has gone from strength to strength, with a quarter of a million young people voting to select the issues debated at the Parliament's annual Commons sitting in November 2012. Members of Parliament who attended the sitting were hugely impressed by the high calibre of the speakers who were amongst the members of the parliament representing their peers from across the country.

\section{UK Youth Parliament 2012}

The 2012 House of Commons Debate took place on Friday 23 November in the House of Commons chamber chaired by the Speaker Rt. Hon. John Bercow MP who said:

"The UK Youth Parliament sitting in the House of Commons has become an annual event of significant importance as indicated by the great numbers of young people who cast their ballot to hear these issues discussed. I am delighted to see 


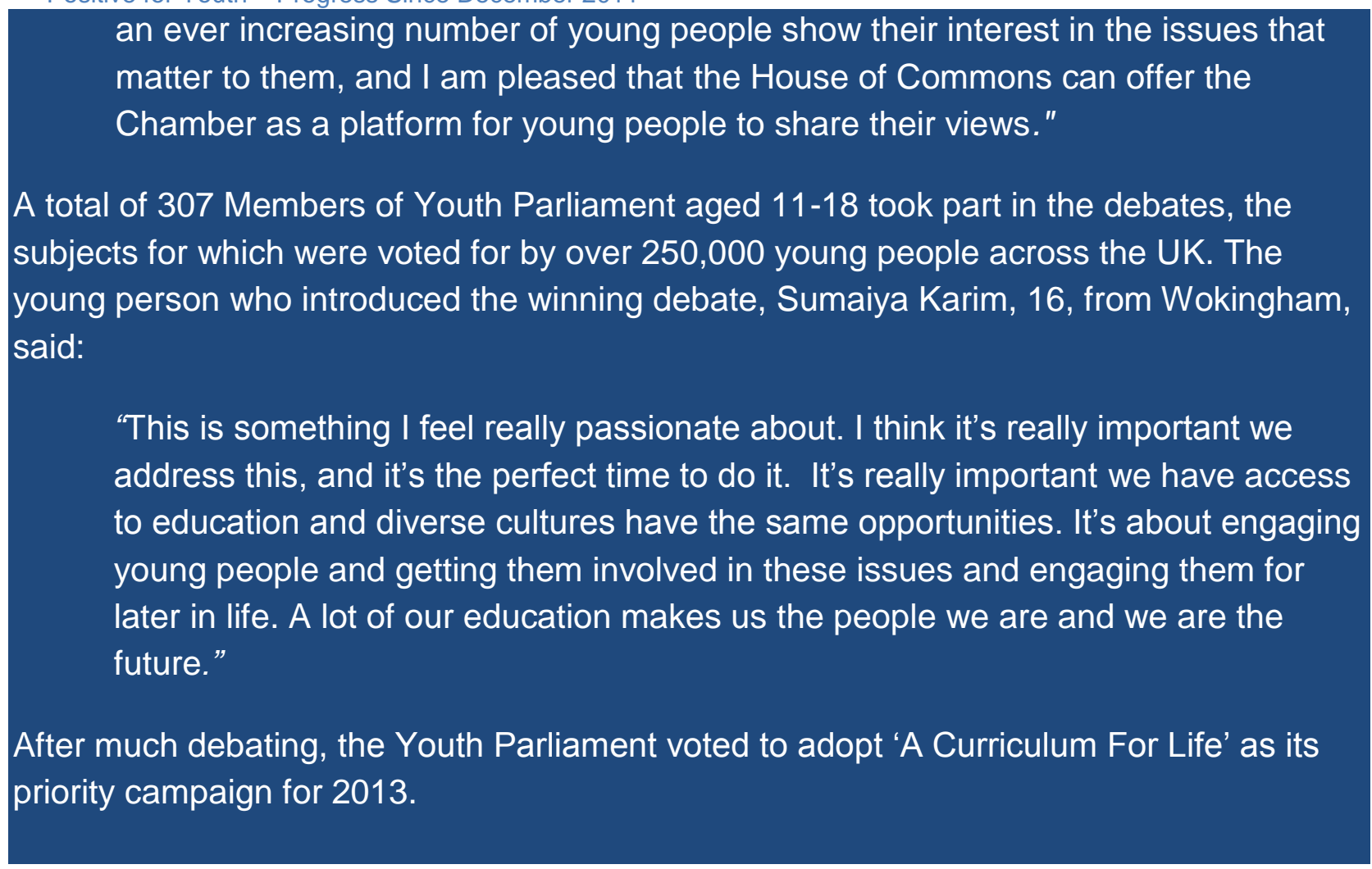

The first session of the Youth Select Committee also took place in July 2012. The Committee, which mirrors the work of Parliamentary Select Committees and is supported in the same way, took evidence from the then Children's Minister, Tim Loughton and the Transport Minister, Norman Baker, as part of its inquiry into safe, affordable and accessible transport for young people. The Committee found that the cost of fares is a key issue for young people using public transport and that young people pay full 'adult' fares at different ages depending on where they live. The Government agreed in principle to many of the Committee's recommendations; it will be reminding LAs of their responsibilities regarding transport and young people. This year the committee will hold an inquiry into "Curriculum for Life".

Last year we also established the National Scrutiny Group of young people, giving them a voice in scrutinising Government policy. The Group met twice during 2012, and discussed policies with officials and Ministers on topics including the Bailey Review of the Commercialisation and Sexualisation of Childhood, HealthWatch and Key Stage 4 exams reform. These fora will continue to ensure that young people's views and perspectives are fully recognised in the process of public policy development.

\section{The Government is committed to continuing to listen to and work with young people.}

It has therefore agreed to continue, for a further two years, providing funding to the British Youth Council in support of the Youth Parliament, Select Committee and National Scrutiny Group. 


\section{Young people at the heart of major Government reforms}

Positive for Youth set out a vision for young people, which touches on the majority of Government Departments as well as local government and its many partners. Each has an important contribution to make to improving outcomes for all young people, and particularly the most disadvantaged and vulnerable.

Since we published Positive for Youth, we have seen the development and delivery of many reforms at a national level, which will have a significant impact on the life chances of young people. We summarise the most important of these below:

\section{An excellent education for all young people}

Education is the most powerful and all-encompassing way of improving the life chances of young people. Over the past year, we have seen acceleration in the pace of reform of the education system, all with a relentless focus on improving standards and ending the inequality in outcomes for disadvantaged young people.

However some young people need extra help to enable them to succeed in education. Over the past year, we have increased the support available to those young people, including the investment of $£ 1.25 \mathrm{bn}$ through the Pupil Premium, which enables schools to support their most disadvantaged pupils.

We have created more choice for young people through the development of more free schools, Studio Schools and University Technical Colleges. And the number of academies - schools where teachers are freed up to deliver the best service for their pupils - now stands at 2,924 (which represents $50 \%$ of secondary schools and $7 \%$ of all primary schools) with more in the pipeline. We are undertaking a fundamental reform of academic qualifications, which has already led to a huge increase in the number of young people taking the core academic subjects - so valued by universities and employers At the same time, we have strengthened accountability to challenge schools to deliver for all young people whilst giving schools and teachers more autonomy through our changes to the National Curriculum.

\section{Putting the power and resources in the hands of those working closest with young people enables them to design and deliver an education that meets the needs of each young person, helping to narrow the attainment gap.}

\section{We are increasing participation and supporting those that need help.}

We are taking a variety of steps to increase participation, including raising the legal age of compulsory participation in education or training - to the end of the academic year in which a young person turns 17 in 2013 and to their 18th birthday in 2015, supported with the investment of $£ 7.335$ billion in 2012-13 and a planned $£ 7.430$ billion in 2013-14 on education and training places for 16-19 year olds. We are creating new 16-19 study programmes for young people from September, including traineeships to help young people prepare for apprenticeships and other sustainable employment. We have 
Positive for Youth - Progress Since December 2011

invested in locally-led delivery projects which are intended to give local authorities the opportunity to test different approaches to achieving full participation and to share their learning with other areas to inform preparations across the country in the build up to 2013/2015.

\section{We have issued guidance to schools and colleges to help them secure high quality, independent careers guidance for young people up to the age of 18 years.}

Well informed decisions about education, training and work options are critical to young people realising their potential. Opening the eyes of young people to the wealth of opportunities available to them can raise their ambitions and encourage them to overcome barriers to success and to pursue the qualifications and skill development necessary to realise their highest potential.

We have begun to transform the system to support pupils with Special Educational Needs, including trialling a single assessment process in advance of bringing forward major legislation. Pathfinders to prevent exclusion by giving schools the resources and responsibility to support pupils are making a positive impact. Virtual School Heads are turning around the chronic underperformance of looked-after children and the Government has announced its intention to make the role statutory. And the voluntary sector continues to make a significant contribution to supporting young people's success.

\section{UK Youth}

UK Youth, working closely with schools, are providing alternative educational provision to some of most marginalised young people who are either excluded or at risk of exclusion. Five Youth Achievement Foundations (YAFs) have been established in a variety of community settings between September 2011 and November 2012. To date 61 young people have re-engaged with education through YAFs.

\section{Support for the most disadvantaged and vulnerable young people}

Over the last year, we have seen again the risks faced by our most vulnerable young people. We recognise, in the light of terrible revelations about child sexual exploitation, that more focus is needed on the safeguarding of adolescents. Reforms over the past year have begun to address that, in particular with the implementation of the Munro review and the delivery of the child sexual exploitation action plan. The Government has supported VCSE organisations, for example through the DfE VCS grants programmes, to develop innovative approaches to supporting disadvantaged and vulnerable young people. Additional funding has been provided to help vulnerable homeless young people into rented homes, and the $£ 448 \mathrm{~m}$ Troubled Families programme has been launched, including work to get young people off the streets and to reduce youth crime. 
Funding provided by the DfE VCS Grants programme has enabled Kids Company to improve the life-chances of acutely vulnerable young people. Through the provision of practical multidisciplinary interventions providing health, social care and education/employment support, Kids Company are addressing the issues fuelling risky behaviours, poor achievement and inconsistent school attendance.

The past year has also seen a focus on young people in care. There has been work to improve placement stability and to increase the provision of adopters and foster carers, including specialist fostering designed to meet the particular needs of young people. A major review of residential care - often the placement of choice for young people - is due to make recommendations shortly on how to improve quality and outcomes for young people. We have strengthened the regulatory framework for looked after children and care leavers to ensure that they are given the same level of care and support that their peers would expect from a reasonable parent. The Parliamentary Under-Secretary of State for Children and Families also has regular meetings with children in care and careleavers, to listen to their views and ensure voices are heard at the heart of Government. All young people can be vulnerable to inappropriate content on the internet, and that is why online safety is now part of the National Curriculum for secondary schools, and is being taught in many primary schools. The UK Council for Child Internet Safety (UKCCIS) Executive Board is attended by key representatives from industry, law enforcement, academia, charities, and is led by Government Ministers.

\section{Youth Contract for $16-17$ year olds}

We have a focused programme of additional support on 16- to 17-year-old young people who are not in education, employment or training (NEET), have low levels of attainment and a range of factors that put them at greater risk of long-term disengagement. The charities and businesses who successfully bid to participate as providers have complete freedom to design and tailor a programme of support to help young people move into fulltime education, an apprenticeship or a job with training. They will receive payment by results (up to $£ 2200$ per person) depending on how successful they are at helping young people to make a sustainable move into a positive outcome. Local authorities (LAs) have a statutory duty to support young people to participate and will have a key role in helping to deliver.

\section{The Government is also working with young people to help them avoid risky behaviours and lead safer lives.}

The Government's Ending Gang and Youth Violence programme has provided funding and support to 29 areas across the country identified as having the most significant gang problems. In January 2013, we extended the offer of support from the frontline team to four additional areas. The programme includes support to stop young people getting involved in gangs and violence in the first place and provide pathways out for others. A 
Positive for Youth - Progress Since December 2011

'One Year On' report was published in November 2012, and set out a series of further cross-government commitments in key areas (http://www.official-

documents.gov.uk/document/cm84/8493/8493.pdf).

\section{Acceptable Behaviour Contracts (ABCs)}

ABCs get individuals to acknowledge their behaviour and its effect on victims, with the aim of stopping problems quickly. Verbal or written warnings can also be very effective at stopping people behaving anti-socially at an early stage. The Government supports the use of early, informal interventions by professionals through restorative and reparative approaches such as these Where more a formal response is required, the Government's proposed new ASB powers will have prohibitions, but can also include positive requirements to help an individual address the underlying causes of their behaviour.

\section{Home Office and NSPCC joint Young People's Panel.}

This group of young people will work to inform the government's ongoing work to tackle domestic violence and wider work to tackle violence against women and girls where it affects young people aged 16 and above.

\section{We are supporting areas affected by gangs.}

The Home Office is providing £1.2m over three years (April 2012 - March 2015) for 13 Young People's Advocates working in areas most affected by gangs. They provide direct and dedicated support to young people who have been victims, or are at risk of, sexual and domestic violence and/or sexual exploitation. We have also announced plans to change the definition of domestic violence and abuse to include those aged 16-17 (currently only those over 18 are included), which should enable better identification and support for vulnerable young people.

\section{Support for the transition into work or further/higher education}

Helping young people to make a successful transition from school has been a key focus for government reform. The introduction of the Youth Contract has provided a major step forward in helping young people into work. This includes around 250,000 work experience placements, cash payments for employers to recruit young people, incentive payments for Small and Medium sized Enterprises and the support the disadvantaged 16 and 17 year olds mentioned above. In addition:

we are introducing traineeships for young people aged 16-19 and will look to extend the programme up to age 24 in due course.

young people are now able to access the Work Programme more quickly and more money is available to providers who find work for young people; 
Positive for Youth - Progress Since December 2011

the roll-out of the Universal Credit will ensure that under 25 s see in-work benefit support when they get a job; and

a number of different trailblazers are underway aimed at supporting young people who have never had a job or who have been on Job Seekers' Allowance for more than 6 months.

Opportunities for young people to experience further and higher education have also been extended, including enabling 14-16 year olds to enrol for further education, and the introduction of the Dux Award, support by the Russell Group universities, which will raise the aspirations of the highest performing secondary school pupils.

\section{Unlocking talent}

DCLG are funding the "Unlocking Talent" scheme, which will bring together pupils from different backgrounds, provide them with business mentors and work experience opportunities, and enable the most committed pupils to go on to establish new enterprises. The scheme will engage 70 schools and 3000 Year 9 pupils aged 13-14 in school partnerships over a three year period 2012/13 - 2014/15.

\section{Social Investment}

The Department of Work and Pensions has announced that it has awarded two contracts worth $£ 7$ million from the Innovation Fund to two social investment partnerships established by social finance. These contracts will fund interventions to work with around 2,500 14-15 year olds who are disadvantaged or at risk of disadvantage to help them participate and succeed in education or training and thereby improve their employability.

DWP also provide support for internships for 16-25 year olds; support for disabled job seekers to help them access support for mainstream job placements; and provision of a wage incentive for employers of disabled young people.

\section{Support for out of school and extra-curricular activities}

The past year has seen major investment in activities that support the personal and social development of young people. One of the most significant of these is the Cabinet Office's National Citizen Service (NCS), a challenging personal and social development programme that, over time, will become available to all 16 year olds. NCS is a lifechanging experience open to all 16 and 17 year olds across England. It is a unique fulltime programme that takes place over three weeks, followed by 30 hours of social action, which benefits both young people and society. Participants build skills for work and life, take on new challenges and adventures, make new friends and contribute to their communities. It is a big demonstration of government's commitment to help young people realise their potential and unlock life chances during these challenging economic times. 
Taking place outside term time, the voluntary programme is made up of four sections that focus on personal and social development including leadership, teamwork and communication skills. Not only do 16 and 17 year olds have the chance to give something back, it helps Young People to develop confidence, self-awareness and responsibility.

The Cabinet Office and the Department for Education piloted NCS during 2011 and 2012 with the participation of around 30,000 young people in 2012. Evidence shows that NCS helps to build participants' confidence and communication, teamwork and leadership skills through volunteering work in their local community. For every $£ 1$ invested in NCS, the programme delivers up to $£ 2$ returns (based on the value of social action and improved educational outcomes). This does not include many of the societal benefits, such as reductions in anti-social behaviour and increased well-being.

In 2013 , around 50,000 places will be available on NCS. In 2014 , we will make
around 90,000 places available.

NCS Graduates

The National Youth Agency (NYA) and partner $\mathrm{O} 2$ Think Big are match funding an additional $£ 500,000$ to give up to 5,000 young people, including 2,500 NCS graduates, the opportunity to start their own social action projects from August 2012 through to September 2013.

NCS sits at the heart of the Government's aim to support social action amongst 10 to 20 year olds. This drive to increase social action amongst young people is being supported across Government, for example through Young Advisors Charity which enables NCS graduates to continue volunteering, gain skills such as leadership, programme management and communication, and mix socially. 434 young people have been trained so far and, by the end of March 2013, this should rise to 670. Independent evaluations and feedback from the young people shows that they found the experience positive. 


\section{The Campaign for Youth Social Action}

The Cabinet Office is working with the new, independent organisation, The Campaign for Youth Social Action, as well as the voluntary sector, schools and businesses to inspire and support a new generation of socially active and responsible young people.

The Campaign seeks to inspire a generation of young people by increasing the quality, quantity and frequency of social action for all young people aged between 10 and 20, ultimately doubling the number of young people participating in social action from $29 \%$ to over $50 \%$ by 2020 .

The Cabinet Office is supporting this by running, in parallel to the Campaign, a fund to support social action programmes in Birmingham, Middlesbrough, Kent and Lancashire. The Youth Social Action Fund, part of the Centre for Social Action, will support:

- social action opportunities for 10-20 year olds, focusing on either programmes which for 10-14 year olds, or programmes that fill a gap in existing provision for other age groups within the 10-20 age range; or

- programmes which support the take-up of, and progression between, social action opportunities for 10-20 year olds, and the overall success of those programmes.

The trials will begin in October 2013.

The ambition for the trials is to:

- Work intensively in a small number of geographic areas to demonstrate the potential for transformation of the landscape of social action opportunities for young people by following the principles of the Campaign for Youth Social Action.

- Support programmes that engage young people in social action activities to adopt the standards and help them expand their reach and impact.

- Learn about how the Outcomes Framework and Quality Mark work in practice.

- Begin to build a longitudinal evidence base which can start to make causal links between youth social action and outcomes for young people, and to share this data with the Campaign.

- Continue to build an understanding of how social action can create positive outcomes for young people, including improved attainment and engagement at school. 
Positive for Youth - Progress Since December 2011

\section{Other extra-curricular opportunities}

A wide range of other opportunities are also now available to young people both in and out of school - in school, disengaged young people are being provided with mentoring and other support through the $£ 1.9 \mathrm{~m}$ military ethos programme and there has been new investment in the establishment of Cadets Units.

\section{Youth United Foundation}

The Foundation is a coalition of the major uniformed volunteering organisations, which engages with and develops young people. Led by HRH The Prince of Wales, the Foundation's purpose is to increase the provision of voluntary youth in areas where they are traditionally limited and aims to recruit 2,700 volunteers and provide places for 10,800 young people. DCLG is investing $£ 10 \mathrm{~m}$ in the programme over $2 \frac{1}{2}$ years.

\section{Youth in Action}

Youth in Action offers a range of opportunities for young people and those working in the youth sector. It is funded by the European Union and administered on behalf of the DfE by the British Council in the UK. It awards grants to groups of young people, individuals, youth workers and organisations to support

- Youth exchanges - groups of young people from across Europe share experiences and learn about the world around them;

- Youth initiatives - young people develop their skills by running their own projects on topics that really matter to them;

Youth democracy -young people develop their understanding of the vital role they play in democratic society and get actively involved;

Youth Voice - supporting the dialogue between young people, youth workers and organisations, and policy makers, to help ensure that young people's voices are heard and that they influence decisions made about them;

- Youth Volunteering - encouraging young people to offer their skills to serve a community as they learn about other cultures, develop language skills and improve their employability;

Training and networking for organisations running Youth in Action projects.

\section{Young people at the heart of local delivery}

National government sets the policy framework and an ambitious reform agenda, but it is at the local level that this comes together for young people. That is why Positive for Youth recognises and celebrates the key role of local leaders in designing and delivering services that meet the needs of their young people. Imposing systems and solutions on 
Positive for Youth - Progress Since December 2011

areas from the centre will not bring about change which meets local needs and circumstances. Positive for Youth put local authorities in the driving seat, and we have followed this over the past year by removing targets and ring-fences on funding, and by clarifying and simplifying guidance and requirements.

\section{We delivered our commitment to refresh the statutory guidance to local authorities on youth services}

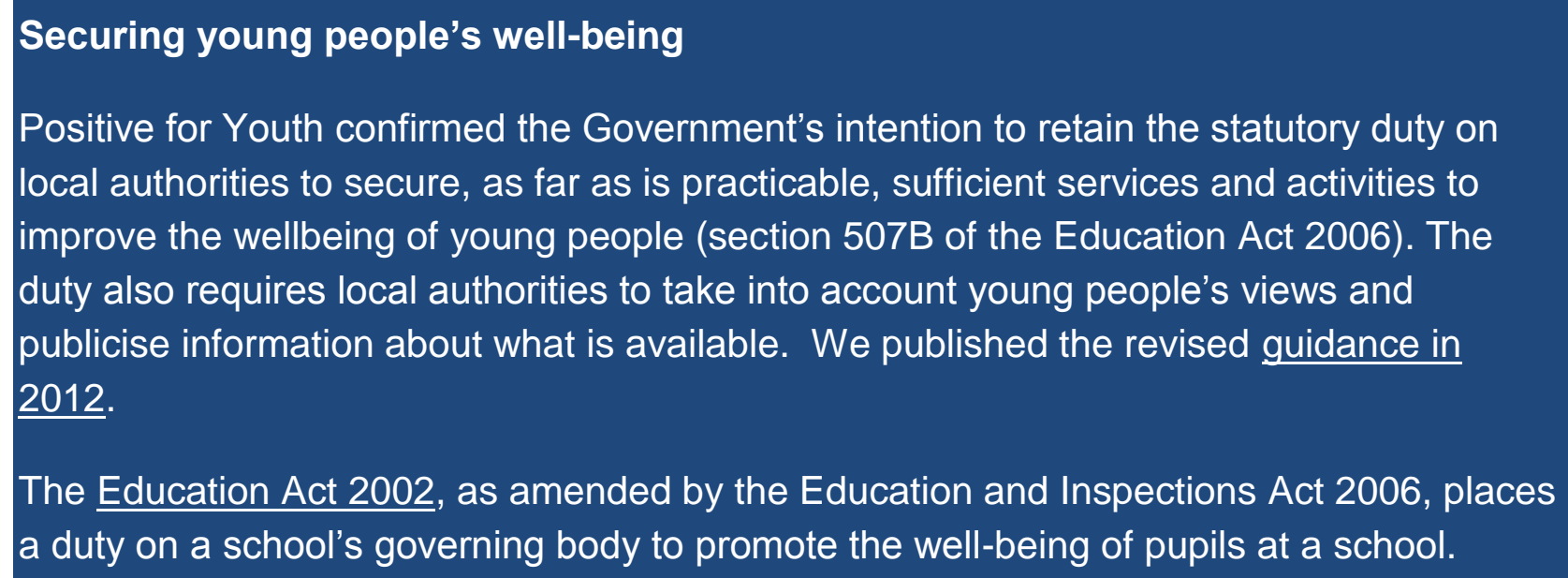

The Education Act 2002, as amended by the Education and Inspections Act 2006, places a duty on a school's governing body to promote the well-being of pupils at a school.

Data on local authority expenditure in 2011-12 shows that authorities spent a total of $£ 876.6$ million (gross) on services for young people, a reduction of $£ 307.5$ million $(26.0 \%)$ compared to $2010-11$, and a total of $£ 338.8$ million (gross) on youth justice, which is a reduction of $£ 73.6$ million (17.8\%) compared with $2010-11$. We also know that total planned expenditure on children and young people's services and social care increased from £8.5bn to £8.6bn (1.3 per cent) between 2011-12 and 2012-13, 2011-12, although there have been some changes to the categories which affect year on year comparisons. The budget for Services for Young People has decreased by $£ 92$ million or $10.4 \%$ (from $£ 883$ million to £791 million) compared with 2011-12. The budget for Youth Justice has decreased by $£ 26 \mathrm{~m}$ or $7.2 \%$ (from $£ 363$ million to $£ 336$ million). However, this does not show the full amount spent on public, private or voluntary sector services from which young people benefit.

\section{Surrey Youth Enterprise workshops}

During 2013 Surrey Youth Focus are running workshops for young people (aged 16-24) and especially for disadvantaged or unemployed (NEET) young people about How To set up in business, whether self- employment or social enterprise. The workshops are free and have two additional elements: provision of business mentor, and aftercare support service from Surrey Youth Focus. This programme is funded by Wates Family Enterprise Trust. 


\section{Castle Vale Youth Council}

Members of the youth council, aged 8-18, actively participate in the Community Forum, which addresses issues relating to community safety and environmental issues, and have helped to organise community days, trips for young people and attended local residents meetings. The Youth Council is supported by Castle Vale Community Housing Association and Castle Vale Community Regeneration Service, and is funded through the Big Lottery Fund. It has also recently had funding from the Tyburn Community First panel.

The transfer of public health from the NHS to local government and Public Health England (PHE) is a significant extension of local government powers and duties, and gives local authorities responsibilities to actively promote health and wellbeing and bring together health and social care services for the benefit of local populations; including young people. This offers the opportunity for local areas to align health promotion services, including improving sexual health, with activities for young people and further contribute to supporting young people's well-being. Single and upper-tier councils will be responsible for a wide range of local public health and health improvement services and will receive a ring-fenced public health budget to meet their new duty.

The Health and Social Care Act 2012 also establishes health and wellbeing boards as a forum where key leaders from the health and care system work together to improve the health and wellbeing of their local population and reduce health inequalities. Boards will be under a statutory duty to involve local people in the preparation of Joint Strategic Needs Assessments and the development of joint health and wellbeing strategies. The process of involvement offers further opportunity for young people to become engaged in issues that affect them and their local communities.

There are strong examples where local authorities have risen to the Positive for Youth challenge, developing new approaches to delivering services and adapting services to reflect new priorities and reduced funding.

\section{Dorset Children's Services}

The Council is prioritising a drive towards increased early intervention and prevention with a view to reducing the need for more specialist services. Integrated teams cover 0 to 19 years at tiers 1 and 2 and include youth workers, children's centre workers and social workers. With the help of the National Youth Agency, it brought together service managers and staff, commissioners, and voluntary and community organisations to draft an outcomes framework, which it is testing with young people.

The Local Government Association, with the support of a $£ 780,000$ grant from Government, has helped services to evolve, innovate and work with other sectors. 
Positive for Youth - Progress Since December 2011

Radical new system-wide approaches are being tested by 14 Youth Innovation Zones including in Salford, Norfolk, Haringey and Somerset.

\section{York Youth Innovation Zone}

The City's Youth Support Services is developing a new cross sector partnership to harness the talents, skills and resourcefulness of staff and volunteers across the statutory, voluntary, community and faith sectors. The local authority facilitates the partnership; it is creating a structure that draws on co-production and agenda setting in which the partners identify areas where co-operation maximises the use of resources. The partnership is piloting new forms of provision for targeted groups.

\section{Bedford Youth Innovation Zone}

9 pilot areas across the Borough set out to work with young people, community members and leaders, community groups and organisations to creatively redesign youth support in local areas and develop the development and sustainability of community led youth provision. Steering groups united local areas, supporting young people to speak at Parish Council meetings, providing opportunities for charities to hear from service users and adapt their delivery and bringing together the voice of young people and adults locally. There have been increased numbers of young people taking part and an increased range of positive activities on offer local to communities (rather than relying on young people travelling to central hubs).

Many other local authorities are taking forward their own approach to addressing young people's needs, working in partnership with local VCSE organisations, sharing best practice with other local areas, and above all, involving young people themselves in the local reforms.

\section{Reading Young Commissioners}

The Council's staff visited several local authorities to observe innovations which they then developed to form a group of 13 to 19 year olds (the "Young Commissioners") which aims to ensure that commissioned services meet young people's needs. The Young Commissioners meet commissioning staff to discuss upcoming work and projects. They have raised awareness and engagement with services, shaped the Sustainable Community Strategy, helped select service providers and been involved in recruiting staff.

Partnerships with local businesses are also contributing to the development of sustainable local provision. Many small and large businesses are keen to share their skills and experience, developing the next generation of employees. Funding from Government has supported the development of some models for brokering work between businesses, local authorities and youth sector organisations. 


\section{New Partnerships - United Futures}

United Futures hold "speed-dating" events to bring businesses and youth sector organisations together, break down barriers and look at new ways of developing crosssector partnerships. Youth organisations are encouraged to think about how business could best fit with their project and practice their 'elevator pitch' before attending the events. 17 youth organisations and 19 businesses for the North West gathered in Liverpool and $91 \%$ reported that they had met someone with whom they were interested in working. All were excited about the prospect of developing mutually beneficial relationships.

United Futures has also brokered five new relationships, which have resulted in improved outcomes for young people in Devon and the businesses' employees:

Ginsters and YMCA Plymouth;

Royal Mail and Youth Devon;

Kier and The Zone;

Amey and Routeways; and

Independent Utilities and The Stone House Play Association.

Local partnerships have also been key to developing and delivering 63 Myplace Centres across deprived areas of England. This Government has invested $£ 141 \mathrm{~m}$ to continue the development of Myplace Centres by partnerships of VCSE organisations, local authorities and private sector organisations, but always with strong leadership from local young people. Centres are transforming local services for young people, by becoming attractive hubs through which they can access a wide range of advice and support services. Some are hosting National Citizen Service teams, others host summer schools and some are providers of programmes of alternative education. Many have close links with local schools.

\section{Myplace Centres}

Walsall Myplace works closely with Joseph Leckie Academy to support young people who are lacking in confidence. This has led to an arrangement for a year 11 young woman who is suffering school phobia, to attend the Myplace Centre, which is next door to the Academy for private study periods so that she can keep up with her preparations for GCSE exams later this year.

\section{We are supporting the voluntary sector.}


Positive for Youth - Progress Since December 2011

The role of VCSE organisations in working with young people is also key. We know that there are more than 34,000 charities in England which mainly serve children and young people, covering a wide variety of areas including social services, employment, training and culture. The work that these organisations do transforms the lives of young people and plays a central role in the development of local and national policy. Funding has been provided to a range of VCSE organisations over the past two years to develop projects which impact on both children and young people and cover a range of DfE priorities. From April 2013, we are providing a further two years of funding to projects which are innovative and nationally scaleable - many of these projects will impact on young people including those with special educational needs or disabilities, those who are in care or adopted, and those who are the most disadvantaged or vulnerable.

During the past year, ministers from across government have benefited from the advice of the Youth Action Group (YAG) - a group which brings together chief executives from the largest VCSE organisations working with disadvantaged young people with a view to discussing and advising Ministers and officials on policy development and delivery. On the Youth Contract - the overall package has various elements which reflect the contribution of the YAG including incentives to employers, opportunities for work experience and particular support for 16 and 17 year olds not in education, training or employment, in recognition that there was a gap in provision for this group.

\section{Mutuals and joint venture partnerships}

One future approach to service delivery by the voluntary sector is through mutuals and joint venture partnerships. Areas such as social work practices, youth services and Sure Start Children's Centres already have established or developing mutuals. Local authorities can pursue these approaches within the existing legislative framework, under the 'Right to Provide' and within the wider spirit of the Government's Open Public Services agenda.

\section{Developing Mutuals in Youth Services}

The Council is looking to form two mutuals for two parts of its youth service - a youth service mutual and a rights and participation services mutual. They are receiving $£ 93,000$ support through the Cabinet Office's Mutuals Support Programme, helping to develop a robust business that is ready to spin out and grow.

Cabinet Office are also supporting youth service spin outs in the Royal Borough of Kensington and Chelsea and the London Borough of Lambeth through the Mutual Support Programme and are aware of 10 applications to Mutuals Information Service in youth support sector. 


\section{The impact of Positive for Youth}

Positive for Youth set out data about a range of factors including trends in attainment, life satisfaction, making a positive contribution to their communities, and participation in risky behaviours. As the vision behind Positive for Youth embeds itself into local and national policy development and delivery, we would hope to see improvements in many of these indicators.

Early indications on some of the measures are encouraging but it would be difficult to attribute any progress to Positive for Youth after 18 months. However, we will continue to use these statistics in the future to assess progress made by young people. In the past year, we have also funded the development and publication of the Outcomes Framework for Young People's Services, which aims to provide a tool for providers and commissioners to measure the impact of their provision.

\section{Outcomes Framework for Young People's Services}

The Framework was developed by the Young Foundation on behalf of the Catalyst consortium to help evidence the impact of services to social investors. It is neither a performance management tool nor mandatory for youth services but:

collates the evidence for the significance of personal and social development to wider outcomes for young people - including education and employment outcomes;

provides a common language to define the core clusters of social and emotional capabilities that evidence shows matter most (such as confidence and agency, resilience, and communications skills); and

Signposts providers and commissioners to the tools that are available for measuring impact against these capabilities.

\section{Increasing numbers of young people in education and work- based learning, and increases in attainment levels}

Raising young people's aspirations and driving up participation and attainment in learning is the best way to help young people realise their potential and prepare for work. Positive for Youth considered whether young people are:

- committed to developing their skills;

- learning to value education and training; and

- increasing their employability;

by using data on the participation in education, employment and training and their attainment by age 19 years. 
The latest provisional figures show that, at the end of $2012,88.1 \%$ of $16-17$ year olds were participating in education and work based learning, and increase of 0.3 percentage points from the end of 2011. The proportion of 18 year olds in Education, Employment or Training fell from $84.7 \%$ at end 2011 to $84.5 \%$ at end 2012 .

Figure 1 Proportion of 18 year olds in Education, Employment and Training (EET) 2007 to 2012

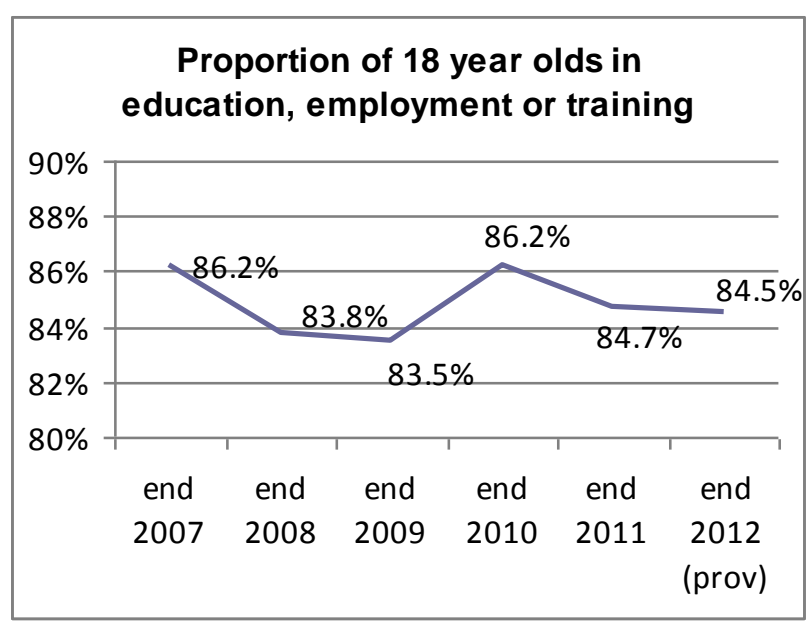

Figure 2 Proportion of 16-17 year olds in Education and Work Based Learning 2007 to 2012

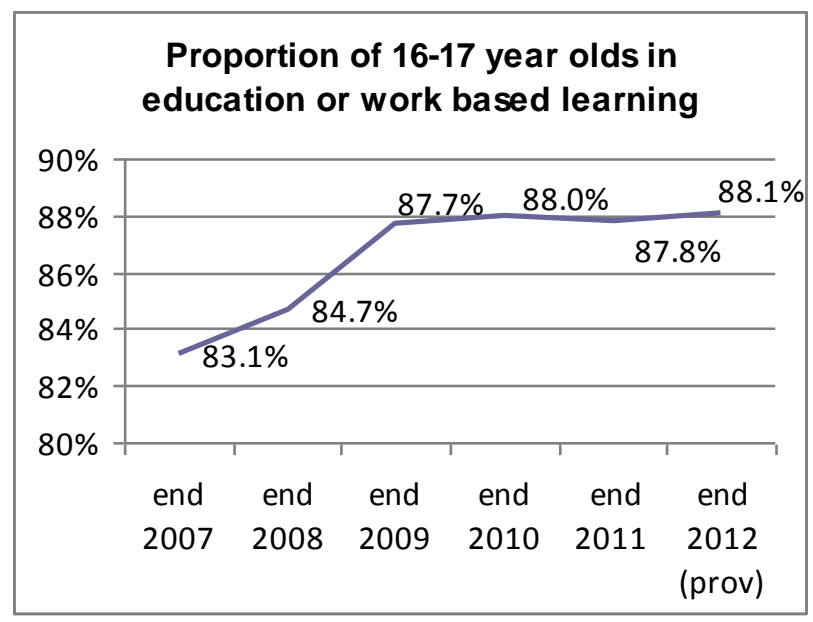

As the table below shows, more females than males were participating in education, employment and training.

\begin{tabular}{|l|l|l|}
\hline & Female & Male \\
\hline $16-17$ year olds in Education and Work Based Learning & $89.3 \%$ & $86.6 \%$ \\
\hline 18 year olds in Education, Employment and Training & $85.1 \%$ & $83.4 \%$ \\
\hline
\end{tabular}

At the same time, the proportion of 19 year olds achieving Level 2 qualifications or higher has increased year on year. In $2011,83.8 \%$ of 19 year olds were qualified to Level 2 or higher, a 2.4 percentage point increase from 2010. Similarly, more young people who were eligible for Free School Meals (FSM) at age 15 years were achieving Level 3. In a reversal of the trend since 2005 the gap between those eligible for FSM at age 15 years 
and their peers increased by 0.5 percentage points between 2010 and 2011. In 2011, $31.8 \%$ of young people eligible for FSM at age 15 years attained Level 3 by age 19 years compared to $56.5 \%$ of their peers - a gap of 24.7 percentage points.

Figure 3 Proportion of 19 year olds achieving Level 3 by FSM status 2007 to 2011

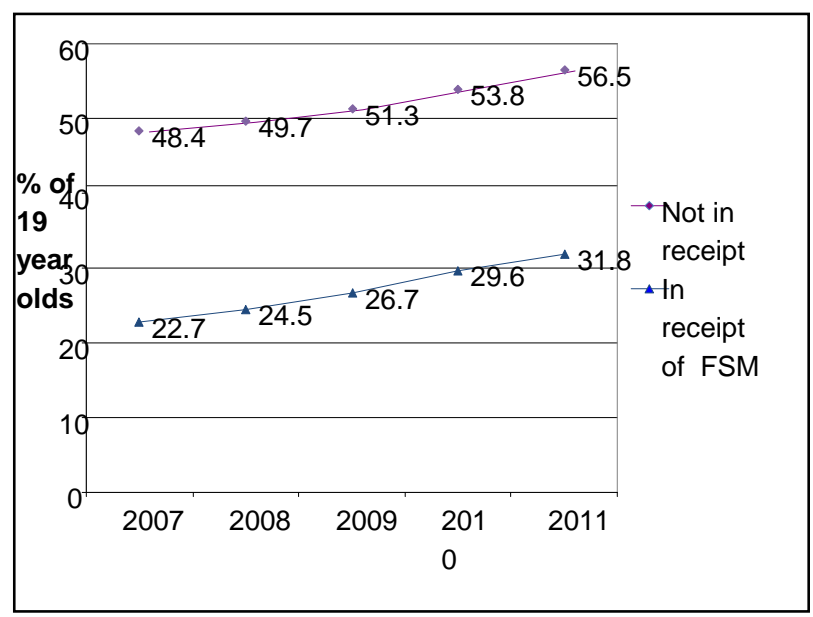

Figure 4 Proportion of 19 year olds qualified to Level 22007 to 2011

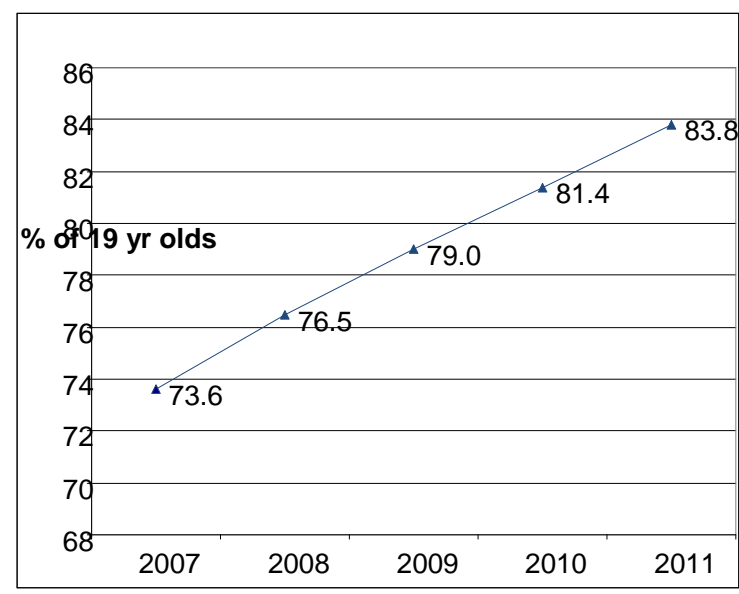

\section{Young people are leading safer and healthier lives...}

Positive for Youth laid down three proxy measures of young people leading safer and healthier lives:

- contact with the criminal justice system;

- alcohol and drugs usage; and

- under 18 years conception.

Across all three measures, progress is very encouraging. Evidence supports the view that suggests that the vast majority of young people do not have any contact with the criminal justice system. In $2011,96.6 \%$ of 10 to 17 year olds had not had any contact with the criminal justice system. This is a significant increase of $0.8 \%$ since 2010 . 
$55 \%$ of $11-15$ year old pupils had never had an alcoholic drink in 2011 . This was at the same level as in 2010. In 2011, 83\% of 11-15 year old pupils had never used drugs, a 1 percentage point increase from 2010.

In 2011, the under-18 conception rate for England was 30.7 conceptions per 1,000 girls aged 15-17. This represents a decline of $10.2 \%$ since 2010 (34.2 conceptions per 1,000) and continues the overall downward trend observed since 1998 when it was 46.6 conceptions per 1,000. The total number of under-18 conceptions in England has declined by $10.4 \%$ since 2010 , down from 32,552 to 29,166 .

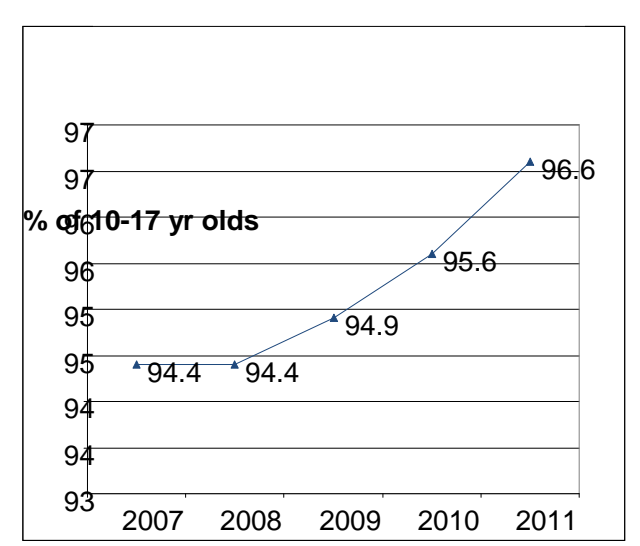

Figure 6 Proportion of 10 to 17 year olds who have not had any contact with the criminal justice system (as measured by a reprimand, warning or conviction) 2006 to 2011

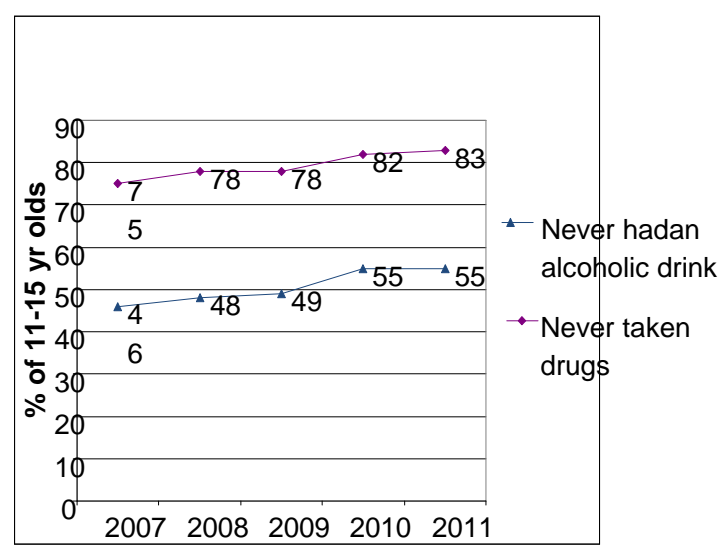

Figure 5 Proportion of 11 to 15 year olds who have ever had an alcoholic drink and ever taken drugs 2007 to 2011

Figure 7 Under 18 years conception rate in England 2006 to 2011

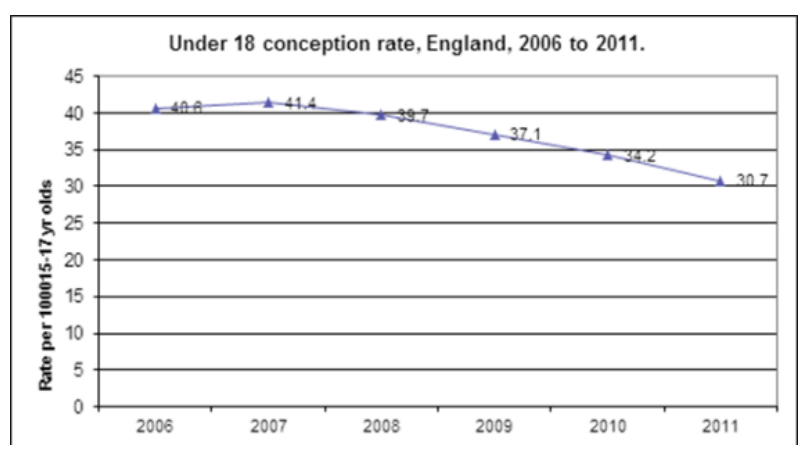

\section{Young people remain active in their local communities....}

Young people can help strengthen their communities and the voluntary sector by volunteering and taking an active role. In Positive for Youth, we said that adults can inspire young people but we should not forget that young people inspire older generations and benefit from relations with adults they trust. 


\section{Gen2Gen Project}

This project is about improving lives by bringing young people and the older generation together. It recruits young volunteers from areas near residential settings for older people, trains them to build rapport with older people and to help them to use modern technology, and then gives them opportunities to put this training into practice. Both generations benefit from and learn to appreciate the other's experience, and gain new skills.

When Positive for Youth was published, the only Official Statistic data available on volunteering was from the Taking Part survey - a national survey of engagement in culture, leisure and sport. Data from this survey in $2011 / 12$ suggested that $31.2 \%$ of 16 19 year olds had been involved in volunteering over the past 12 months, compared with $23.3 \%$ of all adults aged 16 and over. This represented a small (though not statistically significant) decrease from $35.6 \%$ of $16-19$ year olds volunteering in 2010/11.

Since this time the Community Life Survey has been commissioned by the Cabinet Office to provide Official Statistics on issues that are key to encouraging social action and empowering communities, including volunteering, giving, community engagement and well-being. This new Survey incorporates a number of measures from the previously run Citizenship Survey (run by the Department for Communities and Local Government from 2001 to 2010-11) so that trends in certain measures, such as volunteering, can continue to be tracked over time. The Community Life Survey has a wider context than Taking Part, which focuses on culture, leisure and sport, and contains further detail on volunteering measures (e.g. formal and informal volunteering). Further detail on the specific questions included in the Community Life survey can be found at http://communitylife.cabinetoffice.gov.uk

The most recently published Community Life Survey data, covering August 2012 January 2013, show increases in overall levels of both formal and informal volunteering compared with the 2010-11 Citizenship Survey figures. As only two quarter's worth of data have so far been published, it is not possible yet to look at detailed age breakdowns of this data as the sample sizes are not large enough to provide robust information. However the general picture appears to show that the overall increase in volunteering levels also applies to the majority of age groups, including 16-19 year olds where the levels of formal volunteering at least once a year increased from 2010-11 to 2012-13. More detailed breakdowns and analysis will be possible over time as more data is collected and sample sizes increase. 


\section{Redbridge Summer Reading Challenge}

In 2012, 80 young people contributed a total of 2570 hours to the challenge and helped 19764 -11 year old children to read six books over the summer. Following induction and training, the young people engaged with children in their libraries and worked alongside library staff. The result was that libraries capacity to support children increased and they enriched children's experience of the Challenge; parents reported that their children grew in confidence.

\section{Truth about Youth}

Funded by The Co-operative Foundation and delivered in partnership with seven charities across the UK, Truth about Youth is helping to change negative perceptions of young people and build closer communities. The scheme gives young people the chance to prove what they are capable of and break down barriers between age groups.

Kashif Mehboob (20) has been volunteering with Envision, a Truth about Youth partner based in Birmingham, since 2010. Whilst studying for his A-Levels, Kashif set up his own social action project to help challenge stereotypes of young homeless people. He has also mentored others taking part in the programme and is committed to ensuring young people have opportunities to speak up on issues that concern them.

Due to Kashif's commitment to the programme, he was nominated to sit on The Cooperative Foundation's Youth Advisory Panel. Together with six other young leaders from across the UK, he then developed and designed a national campaign to promote positive examples of young people. One year on from the 2011 summer riots, 'One Day' saw young people hosting youth festivals across seven UK cities, to promote the positive contribution young people make to communities. Kashif managed over 30 young volunteers, who organised dancing, art installations and interactions with the public.

'One Day' volunteers engaged with over 2,000 members of the public up and down the country, helping them to stop and think about the way they perceive young people in the UK.

\section{Young people generally feel a sense of well-being....}

Feeling of a sense of well-being is key - how satisfied, happy or anxious young people feel themselves. There is also likely to be an increase in general well-being across the community, as criminal and anti-social behaviour by young people reduces. Positive for Youth draws upon ONS's measure of subjective well-being in which respondents rate 
themselves on a scale of 1 to 10 . This suggests that young people generally feel satisfied with their lives, that the things they do are worthwhile and are happy, with much smaller numbers suggesting that they feel anxious. In 2011-12, young people aged 16-19 had an average life satisfaction rating of 7.8 out of 10 , an average worthwhile rating of 7.7 out of 10 , an average happiness yesterday rating of 7.5 out of 10 , and an average anxious yesterday rating of 2.8 out of 10 . This compares to average mean ratings of 7.4 , 7.7, 7.3, and 3.1 for all adults aged 16 and over.

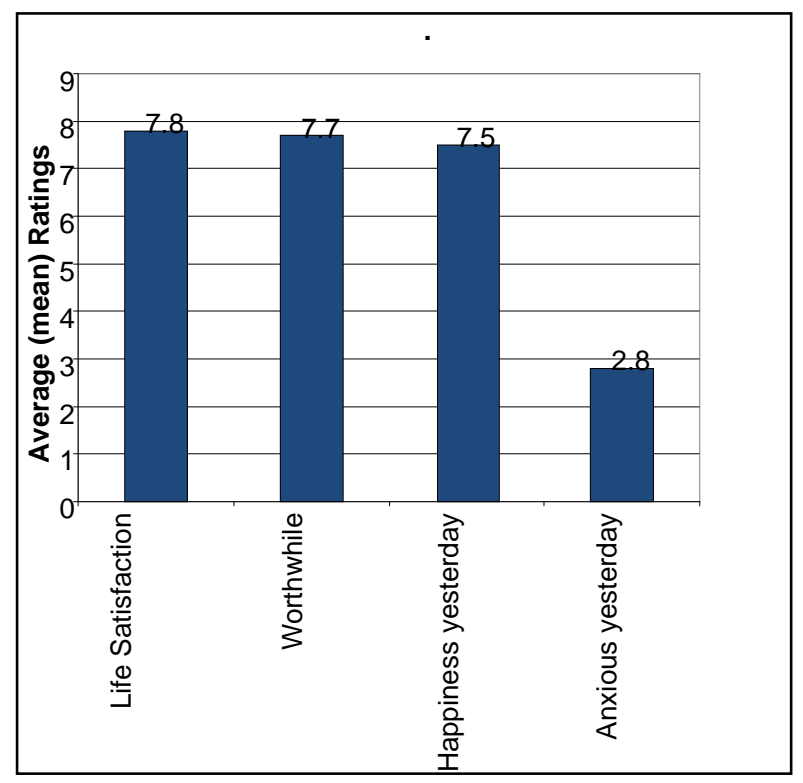

Figure 8 Average (mean) well-being ratings for UK adults aged 16-19 years 2011-12 


\section{Conclusion: Embedding Positive for Youth}

The sustainability of our economy depends upon the health, wellbeing, capability and aspiration of the next generation. That means young people will continue to be the focus of major programmes of reform across Government and of service design and delivery at a local level. Making those reforms a success requires us to listen to the views of young people and inspire and empower them to shape change at every level.

Youth services, which are often pillars of their communities, are rightly led and shaped within those communities. They and the organisations working in them know their needs and those of their young people much better than central government. Decisions about the prioritisation of funding and the provision of young people's services are best made at the local level, taking account of the local context. Central government's role is to give them the freedom and flexibilities to make the most effective decisions such as providing local authorities unringfenced funding and reducing bureaucracy. For that reason, "youth policy is primarily a matter for local government".

The challenge to all those responsible for designing and delivering services, at national and local level, is to continue to:

- engage with and involve young people;

- speak up when they see unfair or unbalanced media reporting;

- take ownership of the vision and leadership of its delivery;

- innovate and evolve as society and its needs change;

- become self-sustaining;

- reduce the dependency on Government for direction, intervention and/or resources;

- actively engage with each other to join up activities and services and avoid unnecessary duplication;

- share information and work in constructive partnerships for the benefit of young people and their communities;

- use and adapt successful initiatives and learn from others; and

- think about the contribution that new partners can make and then draw them in.

\section{Leading by example}

\section{- The Government is committed to the vision that all sectors listen to and work with young people.}

We are determined to lead by example and ensure that we listen to young people and meet the challenge of designing and delivering joined up Government policies and services in consultation with them. We have made a good start through the British Youth Council's work on behalf of the Government relating to youth voice and democracy and the Youth Action Group:

- departments such as Education, Health, and Transport have actively engaged with young people through the UK Youth Parliament, the Youth Select Committee and the National Scrutiny Group; and 
- others, including BIS, DWP, HO, MoJ and DfE, are members of the Youth Action Group which discusses youth unemployment and other youth issue with leading charities;

but Government can do more.

As the list of case studies and commitments shows, departments from across Government are developing and delivering services specifically for young people or which affect young people. It is vital that Government policies and initiatives complement each other and that we avoid duplication. For this reason, we have reviewed the best way to support young people to realise their potential and to deliver the vision of Positive for Youth. We have concluded that there is a compelling case that:

- lead responsibility for youth matters fits better with both the Cabinet Office's policy responsibilities including promoting citizenship and volunteering, encouraging new models of delivery for youth services and public service reform, championing social mobility and democratic participation; and

- the Cabinet Office is better placed, through its role of "supporting collective government, helping to ensure the effective development, coordination and implementation of policy" to coordinate government departments' work on youth issues and champion across government with the Youth Voice arrangements and Youth Action Group.

We will therefore be transferring these roles to the Cabinet Office with effect from July 2013 whilst ensuring that other departments have responsibility for areas of work which they are ideally placed to lead.

\section{DfE Commitment to young people}

The DfE is committed to providing, with the rest of Government, a policy framework which gives them access to an excellent and rigorous education, enables them to progress in future study and work, and supports the vulnerable and disadvantaged when they need it. We will continue to be responsible for education and children's services in England and work to achieve a highly educated society in which opportunity is equal for children and young people, no matter what their background or family circumstances.

The Department will continue to fund the VCS sector in 2013-15 and listen to young people. We will increase participation and support those that need help to succeed in education.

We will work with other departments to deliver the cross government commitments and programmes such as Youth Contract, the Work programme and Youth In Action which increase opportunities for young people and helping them to achieve their potential. We will recognise that other departments and agencies - central and local - are better placed to meet some of the needs of young people and play our part in empowering them to do so. 


\section{Summary}

We have seen the positive impact of Positive for Youth with greater, better participation in every sense and young people reporting a general sense of well-being. They are leading safer, more productive lives.

We have seen examples across the country where local ownership of Positive for Youth is making an impact and where Government is playing its part. People and agencies at all levels are collaborating and innovating to the benefit of their communities and society.

- Government is committed to supporting and enabling that good practice to become the norm.

But there is more each of us can do. Every government department, every agency, every authority and every community has an important role to play.

Government is committed to leading by example by putting young people at the heart of our major reforms and giving others a sense of ownership for their role.

Now is the time to make everything we do and everything we are Positive for Youth.

(C) Crown copyright 2013 
You may re-use this information (excluding logos) free of charge in any format or medium, under the terms of the Open Government Licence. To view this licence, visit www.nationalarchives.gov.uk/doc/open-government-licence or email

psi@nationalarchives.gsi.gov.uk.

Where we have identified any third party copyright information you will need to obtain permission from the copyright holders concerned.

Any enquiries regarding this publication should be sent to us at www.education.gov.uk/contactus.

This document is available for download at www.gov.uk/government/publications. 